Berkeley 6-billion volt bevatron. It uses 36,000 tons of steel in a magnet having an air gap of $2 \mathrm{~m}$. $\times$ $40 \mathrm{~cm}$.; so for the next three or four years the U.S.S.R. will have more powerful machines than the United States. Britain is now far behind both countries in its equipment and work in this most important field of nuclear physics.

In general, we have gained the impression that the U.S.S.R. have an enormous deployment of scientific effort in the field of atomic energy, and that their output of scientists and technologists from their universities is quite adequate to maintain this without starving other activities.

The Conference has been more successful than we had dared to hope from such a large gathering. It has brought together East and West after a long period of separation in the physical sciences. It has been a meeting ground for innumerable friends from all parts of the world. It has enabled us to discuss how best we can help other countries, and has done a great deal to re-establish the normal pattern of communication in the scientific world.

\title{
THE CULCHETH LABORATORIES OF THE UNITED KINGDOM ATOMIC ENERGY AUTHORITY INDUSTRIAL GROUP
}

\author{
By Dr. A. B. McINTOSH
}

$\mathrm{T}$ HE White Paper, "A Programme of Nuclear Power" (Cmd. 9389), has directed attention to the work of the Atomic Energy Authority composed of the Weapons Group (A.W.R.E.), the Research Group (A.E.R.E.) and the Industrial Group. Each is represented by a member of the executive under the chairmanship of Sir Edwin Plowden.

Under Sir Christopher Hinton, its managing director, the Industrial Group is responsible for the design, construction and operation of plants for the production of fissile material and for the prototype nuclear power stations at Calder Hall and Chapel Cross. It is also responsible for advice and guidance to the industrial firms which will undertake the construction of the power stations for the Central Electricity Authority proposed in the White Paper. In collaboration with Harwell, it also pioneers new types of reactors in conformity with the policy laid down in the White Paper.

Within the Industrial Group there are three technical branches: Engineering, Operations, and Research and Development, each under its own director. The design and construction of such projects as the reactors at Calder Hall, Chapel Cross and the large experimental fast reactor at Dounreay are the responsibility of the Engineering Branch. On completion of the plants, the Operations Branch becomes responsible for operation and level of production.

The responsibility of the Research and Develop. ment Branch under its director, Mr. L. Rotherham, is: (1) removal of difficulties which may impede the attainment of full production in any part of a production plant and the development of works processes; (2) provision of information to support the design of now plants and prototype reactors; (3) longer-term study of problems which arise from production plants and design studies.

The Branch works in close collaboration with the Research Establishment at Harwell, which under. takes part of the work.

In the Research and Development Branch, the emphasis is always on the technique at a particular date, and all work is planned and progressed in the same way as the engineering construction programmes to which the major part is intimately linked. It is research applied to industrial needs and not pure research, but in all its work there is close coordination and collaboration with the Research Group at Harwell. This is especially important in the earliest stages, when the feasibility of future reactor systems is being studied.

There are at present four laboratories in the Research and Development Branch, with a fifth in course of formation for work on the Dounreay site. In each of the laboratories there is a large measure of local autonomy and authority. At the Industrial Group Headquarters at Pisley there is a section of the Research and Development Branch working in close collaboration with the design engineers and the headquarters organization of the Operations Branch. Part of the responsibility of this section is that of carrying out theoretical calculations for the four existing laboratories at Capenhurst, Windscale, Springfields and Culcheth.

Except for some specialized fields in which Harwell is responsible, these laboratories, with a scientific and experimental complement of approximately eight hundred, provide a development effort for sanctioned construction projects which are the commitments of the Industrial Group. The Capenhurst Laboratory deals mainly with problems of an engineering nature, such as fluid flow and heat transfer. At Windscale the laboratories are largely devoted to radioactive chemistry, metallurgy and physics, arising from reactor problems at Windscale and Calder and the chemical problems of the plutonium separation process. In Culcheth there is a responsibility for the selection of reactor materials and for work on the extraction of these materials where they may not be commercially available. The small-scale work carried out at Culcheth is then extended to a larger scale at the Springfields Laboratory, which is responsible for the development of fuels and fuel elements.

Culcheth is the only laboratory not on a works site; but it is associated very closely with the Engineering Design Branch at Risley. This gives the laboratories a responsibility for the initiation of work at the feasibility and planning stage of new reactors, especially in the selection of materials for reactor components.

To carry out the commitments of the White Paper, increases in staff in the Research and Development Branch of the Industrial Group are necessary. The Culcheth Laboratories have a present complement of approximately 160 scientific and experimental staff. They are extensively equipped with all the tools required for modern metallurgical research and include laboratories specializing in X-ray diffraction techniques, electron microscopy and ceramics. How- 


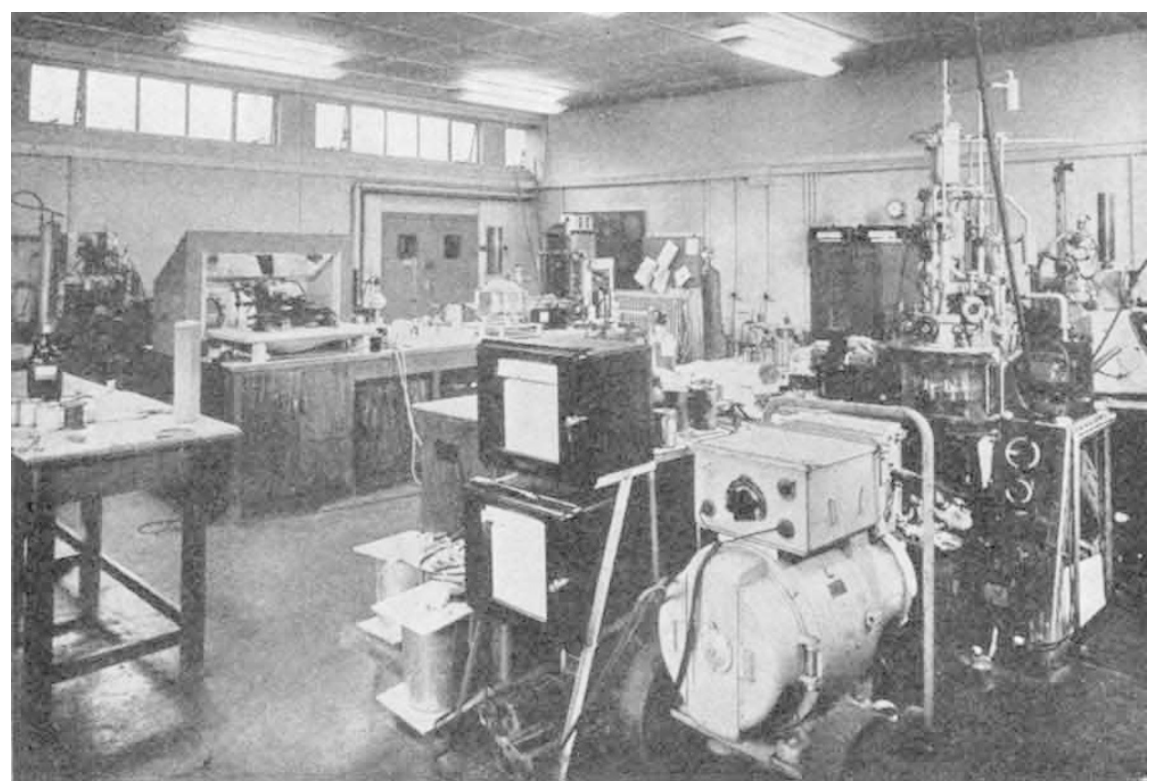

furnace of novel design will be operating in the very near future.

Once the alloys have been prepared, physical and mechanical properties such as thermal conduct. ivity, thermal expansion, creep strength and permeability to gas are measured. The behaviour of the material under various thermal cycling treatments is determined. In those cases where the fuel may come into contact with the coolant, suitable corrosion tests assess the compatibility.

Canning materials. The economic production of electrical power from nuclear reactions demands the highest efficiency at all stages of operation. These demands are made not only on the reactor fuels, but also in the

ever, apart from the large Creep Section and the Materials Inspection Group, both of which have rather special functions, the work of the remainder of the Laboratories is organized to produce results by a planned date for the main programme of engineering construction projects. The objectives of the projects are in all cases the furtherance of the programme of nuclear power development outlined in the White Paper and the development of prototype reactors.

From an overall view, many problems of nuclear power production in the various types of reactor, whether fast fission, thermai or homogeneous, present a common basis. The main questions are of compatibility of materials, the winning of selected metals, the physical metallurgy of chosen alloys and the deformation of metals both in fabrication and under irradiation.

Fuels. When uranium is irradiated, it undergoes dimensional changes which, if sufficiently large, impose stresses on the fuel container. Similar changes are produced by thermally cycling the material, particularly if the cycle includes a phase transformation. These changes affect the life of the fuel elements adversely and limit the operating temperature and the rate of operation of the pile. To achieve the enhanced efficiency and lower production costs visualized in the White Paper, work is in hand. to limit these two forms of irradiation damage.

Two possible methods of reducing irradiation damage are by alloy additions and by suitable heat treatment. The former necessitates manufacturing techniques which are complicated by the extreme chemical reactivity of uranium. These techniques include vacuum or inert atmosphere arc melting, melting by electron bombardment and powder metallurgy. The latter methods are particularly appropriate for the production of fuels which are permeable to gas, a property which may be desirable. It is worth recording that all melting equipment used at Culcheth was designed and built in the Laboratories and includes two d.c. arc furnaces operated from welding generators. An electron-bombardment associated components such as the cans which contain the actual fuel.

In thermal reactors the number of spare neutrons is so small that the paramount requirement for canning materials is that they should have small capture cross-sections for neutrons. If these conditions are to be fulfilled, the most desirable elements for canning include aluminium, beryllium, magnesium and zirconium. These metals do not, however, possess all the other required properties, and work is in progress to assess the improvements which may be achieved by the addition of minor alloying additions to the parent metals.

In fast reactors, the necessity of minimum absorp. tion of neutrons is less important and must be balanced against the need for a metal which can withstand as high a temperature as possible. This focuses attention on the refractory transition metals such as titanium, zirconium, vanadium, niobium, tantalum, molybdenum, tungsten and rhenium. Of these metals, titanium has received considerable attention in recent years as a constructional material, and some of the others have been the subject of research, while most have been used in the form of ferro alloys for additions to steel. At Culcheth, methods have been developed for the extraction of some of these metals in a very pure state, and, for the first time in Britain, vanadium and niobium have been prepared in a ductile form. Techniques have also been devised for the fabrication of these materials, and determinations have been made of their physical and mechanical properties.

It has been found that in some cases a metal or alloy which in other respects possesses highly desirable properties has to be rejected because it reacts with uranium at the appropriate reactor-operating temperature. Methods under investigation to overcome this problem include the deposition of refractory metals from volatile compounds and the use of oxide coatings to separate the fuel from the can.

Breeder materials. In order to maintain and improve stocks of fissile material and to take full advantage of the new types of reactor which promise 


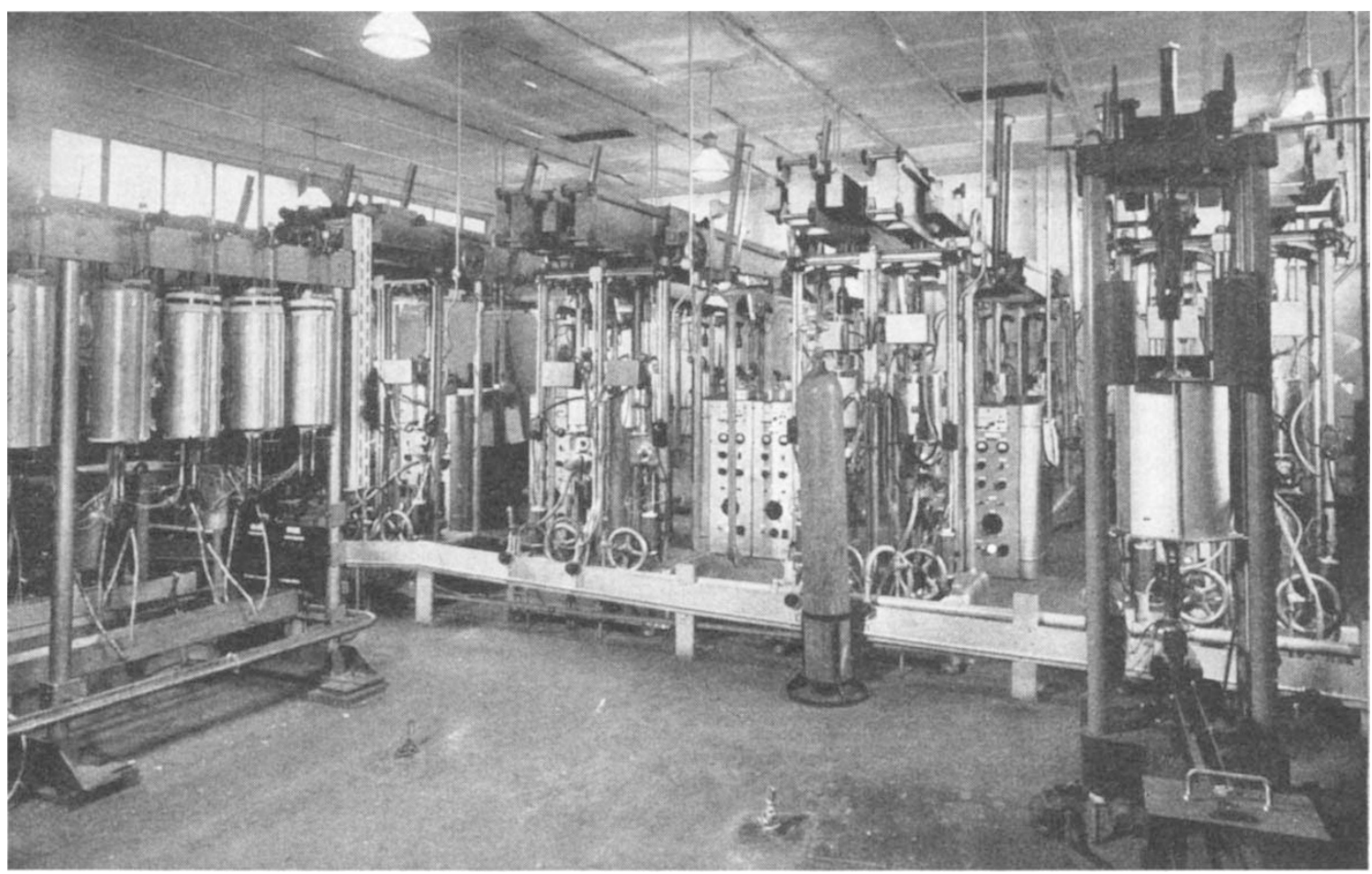

Fig. 2. Creep Laboratory, Culcheth

to be made available as a result of experimental work at Dounreay, it is essential that fresh supplies be obtained by 'breeding' or converting suitable elements. Two such elements are thorium-232 and uranium-238 which, under irradiation, absorb neutrons and then undergo radioactive decay to yield the two fissile materials, uranium-233 and plutonium-239, respectively. The Research and the Industrial Groups have been examining the economic prospects of thorium reactions and, at Culcheth, in viow of the success in the preparation of refractory metals by various methods, similar processes are being examined for the extraction of thorium from monazite.

Coolants. The coolant is the all-important medium through which the heat developed in the core of the reactor will be removed to generate the required steam pressure in the heat-exchanger. Coolants which may be employed in nuclear reactors include water, gases and liquid metals. Not only must the corrosive behaviour of a coolant be investigated, but also many other of its chemical and physical properties, depending on the particular application. As an example, the Dounreay reactor is likely to employ a liquid-metal coolant in the form of sodium-potassium alloy. For this and other liquid metals considered, precise knowledge of ignition temperatures is essential if an accurate estimate is to be made of any hazard which they may present. This ensures that the safety precautions installed are adequate without being exccssive and uneconomical.

Constructional materials. The Atomic Energy Authority's products are such that to contain or process them constructional materials must have, in addition to their normal properties, some feature such as resistance to corrosion in conditions where this is more than usually severe, or where loss by pick-up of a valuable process gas must be avoided. Work is constantly in progress at Culcheth on the examination and improvement of plant materials by the development of new alloys or superior manufacturing techniques. This work frequently results in a com. bination of reduced capital and running costs with an increase in the technical efficiency of a process.

Materials Inspection Group. In any large organization, it is essential that routine tests should be made to ensure that all materials employed are of suitable quality. This service to the Inspection Branch is carried out by a section which also acts as a works metallurgical laboratory for some sections of the Industrial Group. Engineering parts which have received particular attention are brass bellows, water-coolers and bearings.

Creep. The Culcheth Laboratories possess the only creep-testing facilities in the Atomic Energy Authority, and extensive tests have been carried out in inert atmospheres, on a scale probably larger than any attempted elsewhere in Britain. It is believed that, previously, the usual type of precision mirror extensometer had not been used for routine creep tests of materials requiring protection from atmospheric attack, as an enclosed extensometer requires some device whereby, during the course of the test, the mirrors may be reset without breaking a gas seal. The Laboratories have, however, designed, built and successfully operated enclosed mirror extensometers of this type. Materials tested include specimens of proposed canning metals and of uranium itself. Creep-testing machines have also been used for stress-relaxation tests on specimens of the all-welded steel structure of the pressure shell of the thermal reactor under construction at Calder Hall.

Long-term studies as carried out in the Physical Metallurgy and Creep Laboratories aim at providing the basic information for the development of fuels, canning alloys and materials of construction for advanced types of reactors. Fundamental research 
in the Creep Laboratories is at present directed towards the hardening properties of solid solutions, based on aluminium-copper alloys. Starting from this simple alloy, additions of elements with different electron configurations and differing atom sizes can be examined. From this it is hoped to deduce the relationship between the size of the atom and the electron structure, the consequent effect upon hardening and ultimately the creep-strength. Results obtained from a simple alloy should be applicable to the development of reactor materials.

In the long chain of development between the concept of a new reactor and its operation, the Laboratories at Culcheth with their specialized interests in chemistry, physical chemistry and deformation of metals provide an important link.

\section{THE PLANT BREEDING INSTITUTE, CAMBRIDGE}

$\mathrm{O}^{\mathrm{N}}$ July 15 the new buildings and experimental grounds of the Plant Breeding Institute, Cambridge, were officially opened by Mr. D. Heathcote Amory, Minister of Agriculture, Fisheries and Food. The guests of the governing body included the Vice-Chancellor of the University of Cambridge, the Mayor of Cambridge, the City Parliamentary member, officials of the City and County and representatives of the Agricultural Research Council, the Ministry of Agriculture, the National Agricultural Advisory Service, research institutes and university departments.

In his opening remarks the chairman of the governing body, Sir Frank Engledow, paid tribute to the classic work on genetics and plant breeding of the late Sir Roland Biffen, the first director, whose early researches not only stimulated the development of genetic science and its application to the improvement of agricultural plants, but also resulted in the foundation of the Institute in 1912 at the University School of Agriculture. Biffen's work was essentially that of a great individualist who was among the first of the few seientists to appreciate the epochmaking significance of Mendel's genetic work. But Biffen's scientific acumen and imagination led him to apply the new knowledge to crop improvement, and he chose wheat on which to experiment and test the ralidity and value of the new knowledge. This started a new era in plant breeding, and the work at the Institute developed considerably under its two succeeding directors, with the ultimate establishment of the present greatly enlarged research centre.

The Minister, in declaring open the new buildings, said the occasion was significant in marking the fruitful collaboration of agriculture with Cambridge scientists. He welcomed the closer association of scientific research with the task of improving the productivity of British agriculture, and mentioned the great work that had been done in recent years in increasing the output from the farms of Great Britain. $\mathrm{He}$ emphasized the great importance that the Government attaches to agricultural research, and stated that although there has been a recent change in the administration of this research through transfer of control to the Agricultural Research Council, this would not mean any lessening of the Government's interest and support; he, himself, would continue to have the closest association with research work through the Privy Council committee dealing with this important matter.

The director of the Institute, Dr. G. D. H. Bell, coupled his thanks to the Minister with acknowledgments to all who had helped in the task of establishing the Institute in its new home, finally separated from the University. He paid especial tribute to Sir Frank Engledow, not only for his important scientific work in the Institute, but also for his valuable help and guidance, together with that of

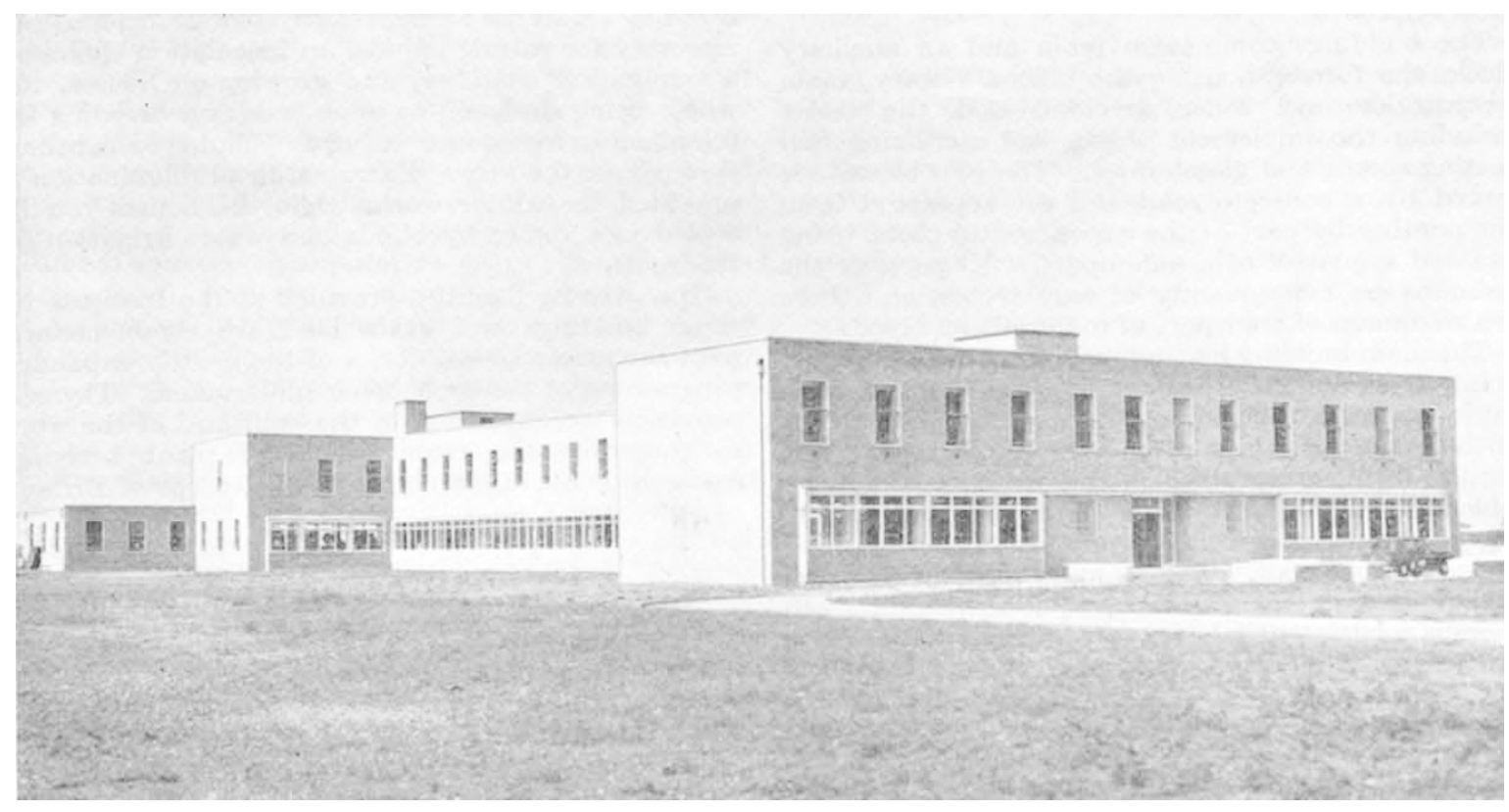
Fig. 1. Plant Breeding Institute, Cambridge, showing the main entrance to the building (right) and the range of laboratories 